This article is licensed under the Creative Commons Attribution-NonCommercial 4.0 International License (CC BY-NC) (http://www.karger.com/Services/OpenAccessLicense). Usage and distribution for commercial purposes requires written permission.

\title{
Recurrent Fever and Failure to Thrive in an 11-Year-Old Boy
}

\author{
Felix Stickel $^{\mathrm{a}, \mathrm{d}} \quad$ Martin Wartenberg $^{\mathrm{b}}$ Hanifa Bouzourene ${ }^{c}$ \\ Maria Anna Ortner ${ }^{d} \quad$ Gerhard Rogler $^{d}$ \\ aHepatology Unit, Klinik Beau-Site, Hirslanden Bern, Bern, Switzerland; 'bnstitute of \\ Pathology, University of Bern, Bern, Switzerland; 'Unilabs Pathology Laboratory, \\ Epalinges, Switzerland; dDepartment of Gastroenterology and Hepatology, University \\ Hospital of Zurich, Zurich, Switzerland
}

\section{Keywords}

Anemia $\cdot$ Celiac disease $\cdot$ Growth retardation · Autoimmune disease $\cdot$ Iron deficiency $\cdot$ Zonulin

\begin{abstract}
Recurrent fever is frequent among children and mostly associated with viral infections inoculated via social contacts with others of the same age. Rarely, severe conditions such as hematological malignancies, pediatric rheumatoid diseases, chronic infections, or inherited recurrent fever syndromes are causative. Herein, we present the case of an 11-year-old boy with frequently recurring high-fever episodes since early childhood, failure to thrive, and iron deficiency who was found to have classical celiac disease (CD) with highly elevated tissue transglutaminase and anti-gliadin antibodies and marked duodenal villous atrophy. Upon implementation of a gluten-free diet, the boy ceased to have fevers, antibodies decreased markedly, his iron status improved, and he significantly gained weight. Although infrequent, recurrent fever should be included into the polymorphic clinical picture of $C D$, and the threshold of testing for diagnostic antibodies should be low in such patients.

(C) 2019 The Author(s)

Published by S. Karger AG, Basel
\end{abstract}




\section{Case Reports in Gastroenterology}

Case Rep Gastroenterol 2019;13:350-356

DOI: $10.1159 / 000502604$

(C) 2019 The Author(s). Published by S. Karger AG, Basel www.karger.com/crg

Stickel et al.: Recurrent Fever and Failure to Thrive in an 11-Year-Old Boy

\section{Background}

Fever in infancy or childhood is frequent and predominantly related to viral or bacterial infections, and only rarely associated with systemic diseases [1]. However, if fevers occur repetitively, in a prolonged fashion, or even in a periodic manner, the differential diagnosis is wide and comprises malignancies [2], immunodeficiency syndromes or autoimmune diseases [3], as well as periodic fever syndromes [4]. The diagnostic workup to reach a correct diagnosis is important in these patients for the implementation of an effective treatment, but often it is complicated, time-consuming, and frequently requires the referral to specialized pediatric centers.

Herein, we present a case of a 10-year-old boy who had recurrent episodes of high fever since the age of 2 years, with normal intellectual development and physical skills but mild growth retardation.

\section{Case Presentation}

An 11-year-old boy was seen by us with repetitive episodes of 5-6 days of agonizing fever above $40^{\circ} \mathrm{C}$ since the early childhood at an irregular frequency of approximately 7-8 times a year. Apart from the fever, no other clinical complaints such as gastrointestinal symptoms including diarrhea, arthralgia, respiratory symptoms, or skin lesions occurred. No overt nutrient intolerance was noticed. At several occasions, detailed workups for infectious causes by the family's general practitioner had unveiled no pathogen. The boy's pharyngeal tonsils were found enlarged on various occasions but never showed deposits. During infancy, the boy had undergone the usual vaccination schedules as recommended. The fever periods were treated with paracetamol and usually subsided after 5-6 days. During fever episodes, the boy was unable to attend school, but during the asymptomatic intervals, he was generally energetic, able to perform well as a football player and showed intellectual abilities clearly above the average. However, a noticeable sign was a relatively small physical size of the boy compared to his 4-year-younger brother and his tall parents.

At the age of 10 years, the fever episodes became more frequent and showed extended lengths of up to 8-10 days, and less responsiveness to antipyretics, which prompted the parents to seek for specialized pediatric attention at the local university hospital as the boy turned 11 years. There, physical examination revealed a body weight of $24 \mathrm{~kg}$ (13.5 percentile, -1.13 standard deviation [SD]), a BMI of 14.03, and height $130.8 \mathrm{~cm}$ (29.6 percentile, -0.37 SD). Other physical findings were unremarkable. Common and rare causes of recurrent fevers were ruled out, including malaria, various autoimmune diseases such as eosinophilia syndromes, mastocytosis, infantile rheumatoid arthritis, vasculitis, hematological malignancies such as acute leukemia, and periodic fever syndromes. At a second referral, rare recurrent fever syndromes such as hyper-IgD syndrome by assuring normal IgD and IgA levels, and tumor necrosis factor receptor-associated periodic syndrome and cryopyrin-associated periodic syndrome were ruled out. To obtain a second opinion, the boy was also referred to another university center, which attained similar inconclusive results. At this stage, the parents were advised to treat the fevers with corticosteroids (prednisolone at $1 \mathrm{mg} / \mathrm{kg}$ body weight), 


\section{Case Reports in Gastroenterology}

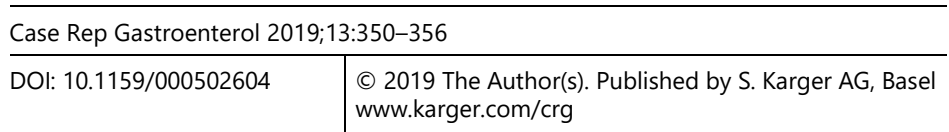
www.karger.com/crg

Stickel et al.: Recurrent Fever and Failure to Thrive in an 11-Year-Old Boy

which were necessary 4 times within the next 12 weeks, with a declining response at every episode.

At each of the consultations, the sole pathological findings were elevated levels of C-reactive protein, iron deficiency, and mild microcytic anemia, which was interpreted in the context of chronic or repetitive inflammation, although serum ferritin levels were also below normal. Routine laboratory tests at first presentation and at the time of establishing the diagnosis are shown in Table 1.

At this time, iron deficiency and microcytic anemia prompted testing for antibodies against tissue transglutaminase (anti-tTGA), which was found markedly elevated at $93 \mathrm{kU} / \mathrm{L}$ (upper limit of normal [ULN] $7 \mathrm{KU} / \mathrm{L}$ ). Next, an upper gastrointestinal endoscopy was performed, which revealed a markedly atrophied duodenal mucosa, but no other abnormalities in the esophagus and stomach. Duodenal biopsies showed a strikingly atrophic duodenal mucosa with marked intraepithelial lymphocytosis, crypt hyperplasia, and villous atrophy compatible with grade IIIb according to the modified Marsh-Oberhuber classification (Fig. 1a, b) [5]. With these findings, the diagnosis of pediatric CD was established, and the boy was subjected to a strict gluten-free diet after instructing his parents. During short-term follow-up, fever episodes stopped instantly and completely until the patient was last seen. Serum levels of anti-tTGA declined markedly to $9 \mathrm{kU} / \mathrm{L}$ (ULN 7) and of anti-EMA to $1 \mathrm{U} / \mathrm{L}$ (ULN 7), reflecting compliance with the dietary requirements. Iron stores recovered following oral iron supplementation, and hemoglobin levels increased to high normal values. The boy gained weight of $6 \mathrm{~kg}$ during 12 months after the diagnosis of CD had been established and reported that his fatigue and weakness had completely disappeared. A follow-up endoscopy with duodenal biopsies revealed a fully recovered mucosal brush border with no evidence of inflammation or duodenal atrophy (Fig. 2a, b).

\section{Discussion and Conclusion}

We herein present an unusual case of CD in a child who showed episodes of high fever since early childhood as the only clinical sign of his underlying disease, and mild anemia and iron deficiency as the key finding leading to the correct, although remarkably delayed, specific laboratory workup and endoscopic examination allowing for the correct diagnosis and specific treatment. A strict gluten-free diet allowed the fever episodes to abate and eventually terminate, while immunological features of $\mathrm{CD}$ and biochemical findings of iron deficiency and anemia normalized.

$\mathrm{CD}$ is a life-long systemic immune disorder in genetically susceptible individuals triggered by exposure to gluten and its related prolamins contained in wheat, barley, oat, and rye. The classical clinical presentation comprises diarrhea, abdominal pain, and distension, growth retardation, and numerous extraintestinal, often dermatological manifestations [6, 7]. The enigmatic clinical presentation of CD is well known [8-10], but fever as the isolated clinical symptom is rare and has been described only in a few pediatric cases associated with hemophagocytic lymphohistiocytosis, which responded well to a gluten-free diet $[11,12]$.

Pathophysiologically, fever results from the production and release of proinflammatory cytokines with pyrogenic activity such as interleukin-1, interleukinL-6, tumor necrosis factor- $\alpha$, and interferons. Pyrogenic mediators, in particular prostaglandin E2, generated from 


\section{Case Reports in Gastroenterology}

Case Rep Gastroenterol 2019;13:350-356

DOI: $10.1159 / 000502604$

(c) 2019 The Author(s). Published by S. Karger AG, Base www.karger.com/crg

Stickel et al.: Recurrent Fever and Failure to Thrive in an 11-Year-Old Boy

arachidonic acid in cell membranes, act on the anterior hypothalamus in the central nervous system and raise the set point for temperature followed by processes that elevate body temperature. The immunological dysfunction underlying $\mathrm{CD}$ is that of an aberrant T-helper cell 1 (Th1) and 2 (Th2) recruitment. This leads to the activation of autoreactive Th cells followed by the subsequent release of proinflammatory cytokines [13], which in turn activate intraepithelial lymphocytes that cause histological mucosal damage in the duodenum [14].

Another hypothesis as to how pyrogenic mediators may induce fever in CD is related to zonulin, the only known physiological modulator of mucosal integrity by modulating the patency of tight junctions. Increased zonulin levels cause a loss of the mucosal barrier function and allow the entry of intestinal contents such as dietary components, bacterial lipopolysaccharides, and endotoxins that may function as proinflammatory stimulators in the liver and other organs. Interestingly, increased levels of zonulin have been reported in patients with CD $[15,16]$ with gliadin as a potent inducer of zonulin release [17]. However, in our patient, an immune-mediated mechanism of pyrexia seems more likely as the fever episodes terminated abruptly once a gluten-free diet had been established. If a mucosal barrier dysfunction would have been pivotal for the precipitation of fever in our patient, symptoms should have persisted since mucosal damage is not expected to heal so quickly.

In our view, the latency until a correct diagnosis had been reached in this young patient is remarkable, but not entirely surprising considering the plethora of symptoms by which CD can present initially. In 2007, the Canadian Celiac Association reported the clinical presentation of 2,681 patients with biopsy-proven celiac disease with the most common features being abdominal pain (83\%), diarrhea (76\%), and weight loss (69\%). Failure to diagnose CD was often due to ascribing the symptoms to anemia (40\%), stress (31\%), and irritable bowel syndrome (29\%). The latter may well explain the reported delay of 11.7 years until the correct diagnosis was made in this cohort study, mainly due to misinterpretation and trivialization of symptoms [18].

Considering the high prevalence of $\mathrm{CD}$ in the United States and in most Western and Middle Eastern countries of approximately 1\% [19], and of $>3 \%$ in patients with iron-deficiency anemia [20], the threshold for serological testing for CD should be low, particularly since antibody testing is now widely available and relatively affordable.

\section{Statement of Ethics}

Written informed consent was obtained from the patient and his parents who agreed to have the boy's medical details submitted for publication anonymously.

\section{Disclosure Statement}

The authors declare that they have no conflicts of interest to disclose. 


\section{Funding Sources}

No specific funding was assigned to this work.

\section{Author Contributions}

Felix Stickel: conceived the report, collected data, wrote the manuscript, and approved its final version.

Martin Wartenberg: provided and analyzed the histopathology slides, critically revised the manuscript, and approved its final version.

Hanifa Bouzurene: provided and analyzed the histopathology slides, critically revised the manuscript, and approved its final version.

Maria Anna Ortner: collected clinical data, critically revised the manuscript, and approved its final version.

Gerhard Rogler: supervised the analysis, critically revised the manuscript, and approved its final version.

\section{References}

1 McIntyre J. Management of fever in children. Arch Dis Child. 2011 Dec;96(12):1173-4.

2 Clarke RT, Van den Bruel A, Bankhead C, Mitchell CD, Phillips B, Thompson MJ. Clinical presentation of childhood leukaemia: a systematic review and meta-analysis. Arch Dis Child. 2016 Oct;101(10):894-901.

3 Rigante D. Autoinflammatory syndromes behind the scenes of recurrent fevers in children. Med Sci Monit. 2009 Aug;15(8):RA179-87.

4 Lachmann HJ. Periodic fever syndromes. Best Pract Res Clin Rheumatol. 2017 Aug;31(4):596-609.

5 Green PH, Rostami K, Marsh MN. Diagnosis of coeliac disease. Best Pract Res Clin Gastroenterol. 2005 Jun;19(3):389-400.

6 Doganci T, Bozkurt S. Celiac disease with various presentations. Pediatr Int. 2004 Dec;46(6):693-6.

7 Leggio L, Abenavoli L, Parente A, de Lorenzi G, Gasbarrini G, Addolorato G. Celiac disease and skin disorders. Pediatr Dermatol. 2005 Jul-Aug;22(4):376-7.

8 Salmeron G, Patey N, de Latour RP, Raffoux E, Gluckman E, Brousse N, et al. Coeliac disease and aplastic anaemia: a specific entity? Br J Haematol. 2009 Jun;146(1):122-4.

9 Volta U, De Franceschi L, Lari F, Molinaro N, Zoli M, Bianchi FB. Coeliac disease hidden by cryptogenic hypertransaminasaemia. Lancet. 1998 Jul;352(9121):26-9.

10 Corazza GR, Andreani ML, Venturo N, Bernardi M, Tosti A, Gasbarrini G. Celiac disease and alopecia areata: report of a new association. Gastroenterology. 1995 Oct;109(4):1333-7.

11 Cooney MJ, El-Matary W. Celiac disease presenting as Fever of unknown origin. Case Rep Gastrointest Med. 2013;2013:676327.

12 Fordham NJ, Ajitsaria R, Karnik L, Chakravorty S. Hemophagocytic lymphohistiocytosis responding to withdrawal of gluten: a case report. J Med Case Reports. 2016 Sep;10(1):262.

13 Heydari F, Rostami-Nejad M, Moheb-Alian A, Mollahoseini MH, Rostami K, Pourhoseingholi MA, et al. Serum cytokines profile in treated celiac disease compared with non-celiac gluten sensitivity and control: a marker for differentiation. J Gastrointestin Liver Dis. 2018 Sep;27(3):241-7.

14 Schuppan D, Junker Y, Barisani D. Celiac disease: from pathogenesis to novel therapies. Gastroenterology. 2009 Dec;137(6):1912-33.

15 Fasano A, Not T, Wang W, Uzzau S, Berti I, Tommasini A, et al. Zonulin, a newly discovered modulator of intestinal permeability, and its expression in coeliac disease. Lancet. 2000 Apr;355(9214):1518-9.

16 Drago S, El Asmar R, Di Pierro M, Grazia Clemente M, Tripathi A, Sapone A, et al. Gliadin, zonulin and gut permeability: effects on celiac and non-celiac intestinal mucosa and intestinal cell lines. Scand J Gastroenterol. 2006 Apr;41(4):408-19. 


\section{Case Reports in Gastroenterology}

\begin{tabular}{l|l}
\hline Case Rep Gastroenterol 2019;13:350-356 \\
\hline DOI: 10.1159/000502604 & $\begin{array}{l}\text { @ 2019 The Author(s). Published by S. Karger AG, Basel } \\
\text { www.karger.com/crg }\end{array}$ \\
\hline
\end{tabular}

Stickel et al.: Recurrent Fever and Failure to Thrive in an 11-Year-Old Boy

17 Thomas KE, Sapone A, Fasano A, Vogel SN. Gliadin stimulation of murine macrophage inflammatory gene expression and intestinal permeability are MyD88-dependent: role of the innate immune response in Celiac disease. J Immunol. 2006 Feb;176(4):2512-21.

18 Cranney A, Zarkadas M, Graham ID, Butzner JD, Rashid M, Warren R, et al. The Canadian Celiac Health Survey. Dig Dis Sci. 2007 Apr;52(4):1087-95.

19 Mahadev S, Laszkowska M, Sundström J, Björkholm M, Lebwohl B, Green PH, et al. Prevalence of Celiac Disease in Patients With Iron Deficiency Anemia-A Systematic Review With Meta-analysis. Gastroenterology. 2018 Aug;155(2):374-382.e1.

20 Gatti S, Lionetti E, Balanzoni L, Verma AK, Galeazzi T, Gesuita R, et al. Increased Prevalence of Celiac Disease in School-age Children in Italy. Clin Gastroenterol Hepatol. 2019 Jun;S1542-3565(19)30651-2.

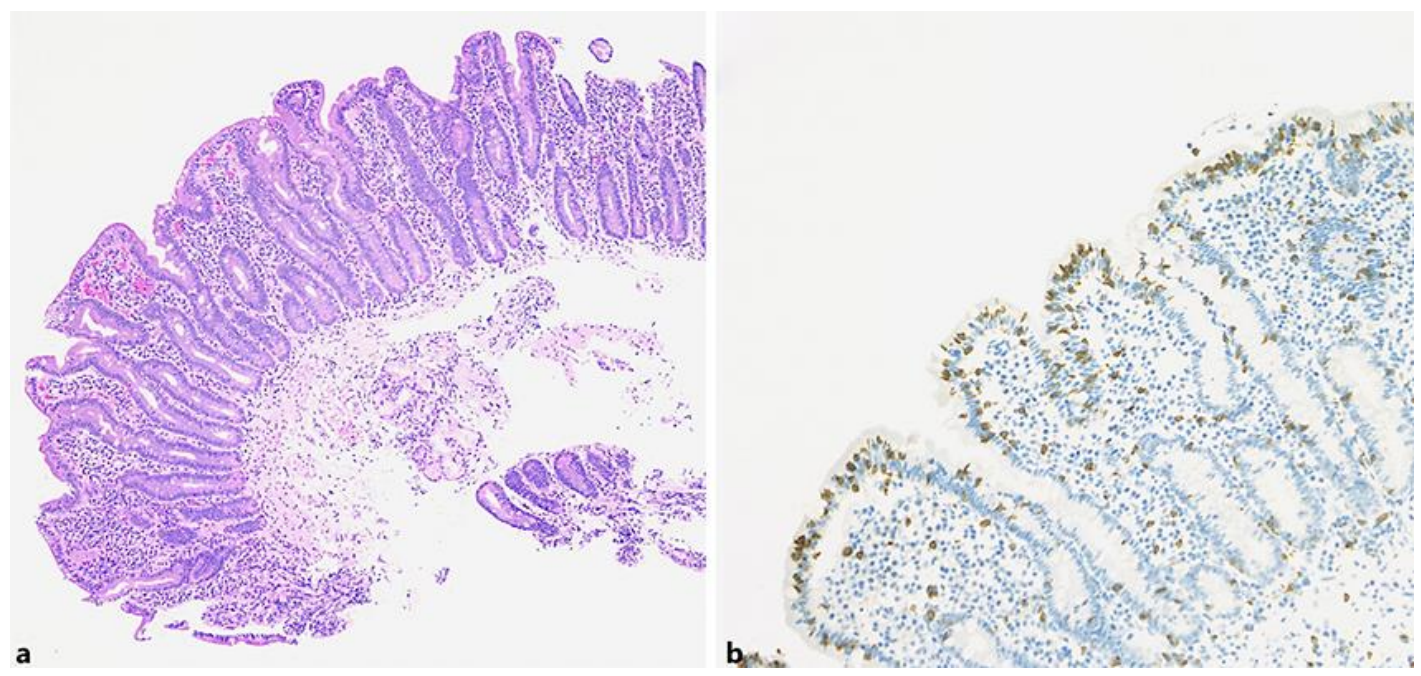

Fig. 1. a Histology image showing the duodenum prior to gluten-free nutrition at the time of diagnosis of CD. Clearly visible is the profound villous atrophy. Hematoxylin-eosin staining. Magnification, 1:100. b Corresponding immunohistology using monoclonal CD8 antibodies demonstrating invasion of intraepithelial lymphocytes. Magnification, 1:200. 

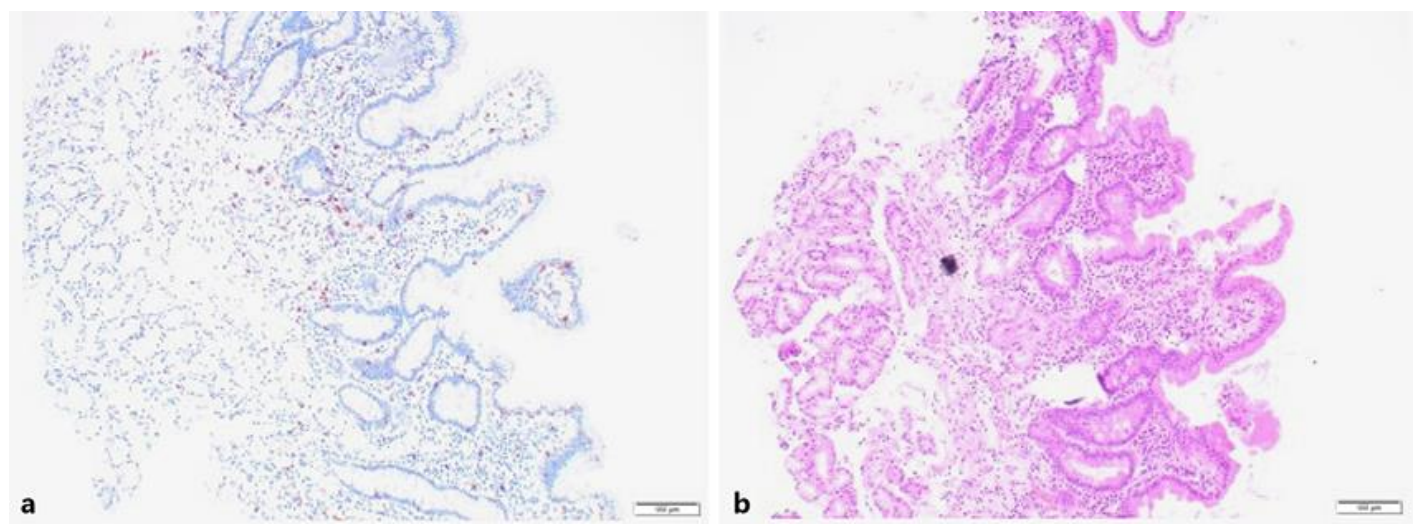

Fig. 2. a Histology image showing the duodenum following 18 months of strict gluten-free diet. Villous atrophy is no longer visible. Hematoxylin-eosin staining. Magnification, 1:100. b Immunohistology from the same mucosal specimen using monoclonal CD8 antibodies following 18 months of strict gluten-free diet. Only scarce CD8 positivity can be detected. Magnification, 1:100.

Table 1. Laboratory examinations at diagnosis and after 18 months of gluten-free diet

\begin{tabular}{lll}
\hline Variable (normal range) & TP1 & TP2 \\
\hline Hb $(135-175 \mathrm{~g} / \mathrm{L})$ & 107 & 132 \\
$\mathrm{Hct}(0.41-0.53 \mathrm{~L} / \mathrm{L})$ & 0.32 & 0.40 \\
MCV $(77-95 \mathrm{fL})$ & 72 & 81 \\
Serum iron $(4.4-35.6 \mu \mathrm{mol} / \mathrm{L})$ & 4.3 & 10.5 \\
Ferritin $(30-300 \mu \mathrm{g} / \mathrm{L})$ & 23 & 113 \\
Transferrin saturation $(16-45 \%)$ & 9 & 19 \\
CRP $(<10 \mathrm{mg} / \mathrm{L})$ & 95 & 0.6 \\
Anti-tTGA (<10 kU/L) & 93 & 9 \\
Anti-gliadin IgA (<7 U/L) & nd & 1 \\
ALT $(<41 \mathrm{U} / \mathrm{L})$ & 15 & 19 \\
\hline
\end{tabular}

ALT, alanine aminotransferase, anti-tTGA, anti-tissue transglutaminase; CRP, C-reactive protein; Hb, hemoglobin; Hct, hematocrit; MCV; mean corpuscular volume; nd, not done; TP1, time point 1 (diagnosis); TP2, time point 2 (treatment follow-up). 